\title{
High resolution seismic refraction data interpretation: an example from Xiakou landslide, Sichuan, China
}

\author{
Surendra Raj Pant ${ }^{1}$, T. $\mathbf{L i}^{2}$, A. Wagner ${ }^{3}$, Fu Wei $\mathrm{Yi}^{4}$, and Cao Jiaman ${ }^{4}$ \\ ${ }^{1}$ Central Department of geology, Tribhuvan University, Kirtipur, Kathmandu, Nepal \\ ${ }^{2}$ Mountain Enterprises and Infrastructure Division, International Centre for Integrated Mountain \\ Development (ICIMOD), Kathmandu, Nepal \\ ${ }^{3}$ Chemin des Recluses 5, 1213 Petit-Lancy, Geneva, Switzerland \\ ${ }^{4}$ Department of Geophysics, Chengdu Technical Institute, 610059 Chengdu, People Republic of China
}

\begin{abstract}
Among several data processing and interpretation techniques available in seismic refraction, the Generalised Reciprocal Method (GRM) is now widely used. In the thick landslide zone of Xiakou, Sichuan, China, the depths to bedrock obtained from the conventional refraction interpretation by the Plus-Minus Method (Method $t_{0}$ ) differed considerably from the results of electrical soundings and drilling. The conventional methods were not able to accommodate to the more likely geological situations (i.e. undetected layers and velocity inversion) in a thick landslide zone. Thicker the overburden more the variation occurred between the results of the GRM and conventional methods. The velocity of seismic waves in the refractor calculated by the Plus-Minus Method was also affected significantly from the bedrock topography. After applying the GRM, the calculated depths were found to be very near to those of the drilling and electrical sounding. The GRM also revealed that the changes in refractor velocity (recorded by conventional methods) were fictitious. The fictitious changes in refractor velocity were caused by the target refractor topography and surface topography.

In this paper two profiles are taken for discussion. The profile B-B' represents a case of thick overburden (more than $30 \mathrm{~m}$ ) whereas the profile $\mathrm{D}^{-\mathrm{D}^{\prime}}$ is taken from a thin overburden (less than $15 \mathrm{~m}$ ) above the target refractor.
\end{abstract}

\section{INTRODUCTION}

Landslides and critical slopes along highways are investigated by various geophysical methods. Among them the seismic refraction and geoelectrical methods are more popular. The methods are able to provide information related to material type, water table, and depth to bedrock. However, the interpretation conducted by conventional methods becomes less reliable in some landslides owing to extreme lateral and vertical inhomogeneities. In the past, it was the cause to refuse the application of geophysical methods in landslides and other critical slopes. Furthermore, the analyses conducted by conventional methods failed to provide reliable refractor topography and velocity information. The $\mathrm{P}$-wave velocity information is very useful for estimating the rippability, rock quality, and locating fractures and faults in the rock. The reliable depth information provided by seismic refraction is also equally important for designing engineering structures. In the conventional method, several fictitious velocity changes in the refractor were interpreted as faults and weak zones. In most of the cases, these 'zones' were induced by the geometry of the refractor or the surface topography.

The study area is located about $9 \mathrm{~km}$ north of the Yaan City, Sichuan, South-Western Central China (Fig. 1). The area was investigated by several seismic profiles and geoelectrical soundings (Fig. 2). Previously, the area was also investigated by drilling a borehole. The hole was located near the start of the profile $\mathrm{A}-\mathrm{A}^{\prime}$. It showed a multi-layered sequence of gravel and boulders, and boulders mixed with clay. The target refractor consisted of a series of 


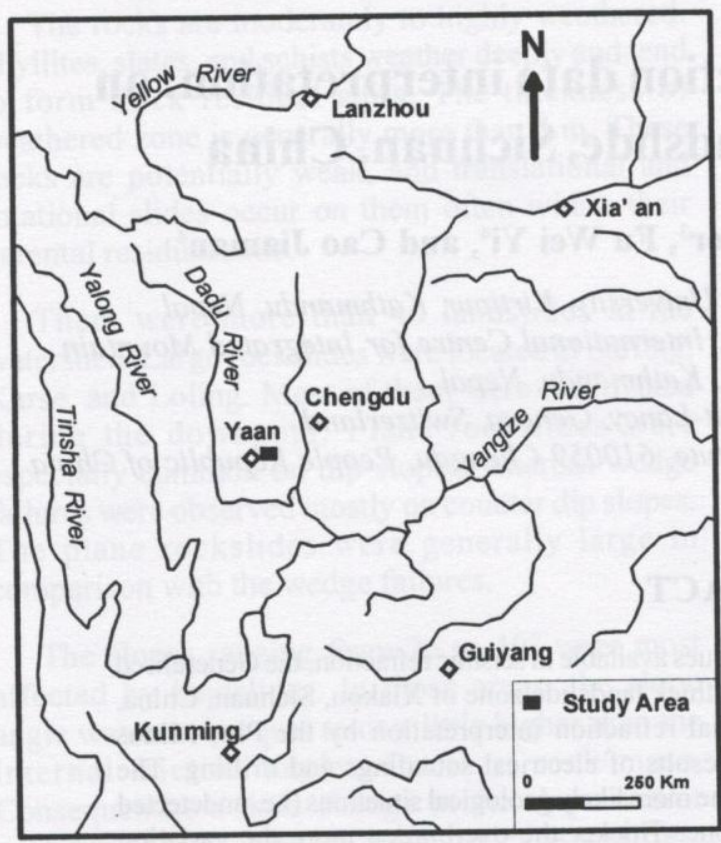

Fig. 1: Map of South-Western Central China showing the study area sandstone, claystone, and silty-claystone. The total thickness of overburden revealed by the borehole was $40 \mathrm{~m}$. The distribution of various material types within the overburden favoured the formation of a perched water table. The results of the drilling and geoelectrical soundings indicated that the overburden was clay-dominant soil and its thickness varied from place to place, ranging from 5 to $45 \mathrm{~m}$ (ICIMOD 1996). During the monsoon, the landslide used to creep down the slope and block the Lunxi River. It caused inundation of the Yaan City several times in the past.

In an area where the overburden above the target refractor is relatively thick (probably more than 15 $\mathrm{m})$, the presumed criteria for the refractor usually do not meet. The hidden layers and velocity inversion in the overburden make the calculated depths to differ significantly from the actual ones. In the conventional engineering seismic refraction, it is a usual practice to estimate the average velocity of overburden by taking the effective velocity (Gurvich 1972). The interpretation based on the effective velocity usually gives satisfactory results only when the refracted waves are observed from all the layers of overburden.

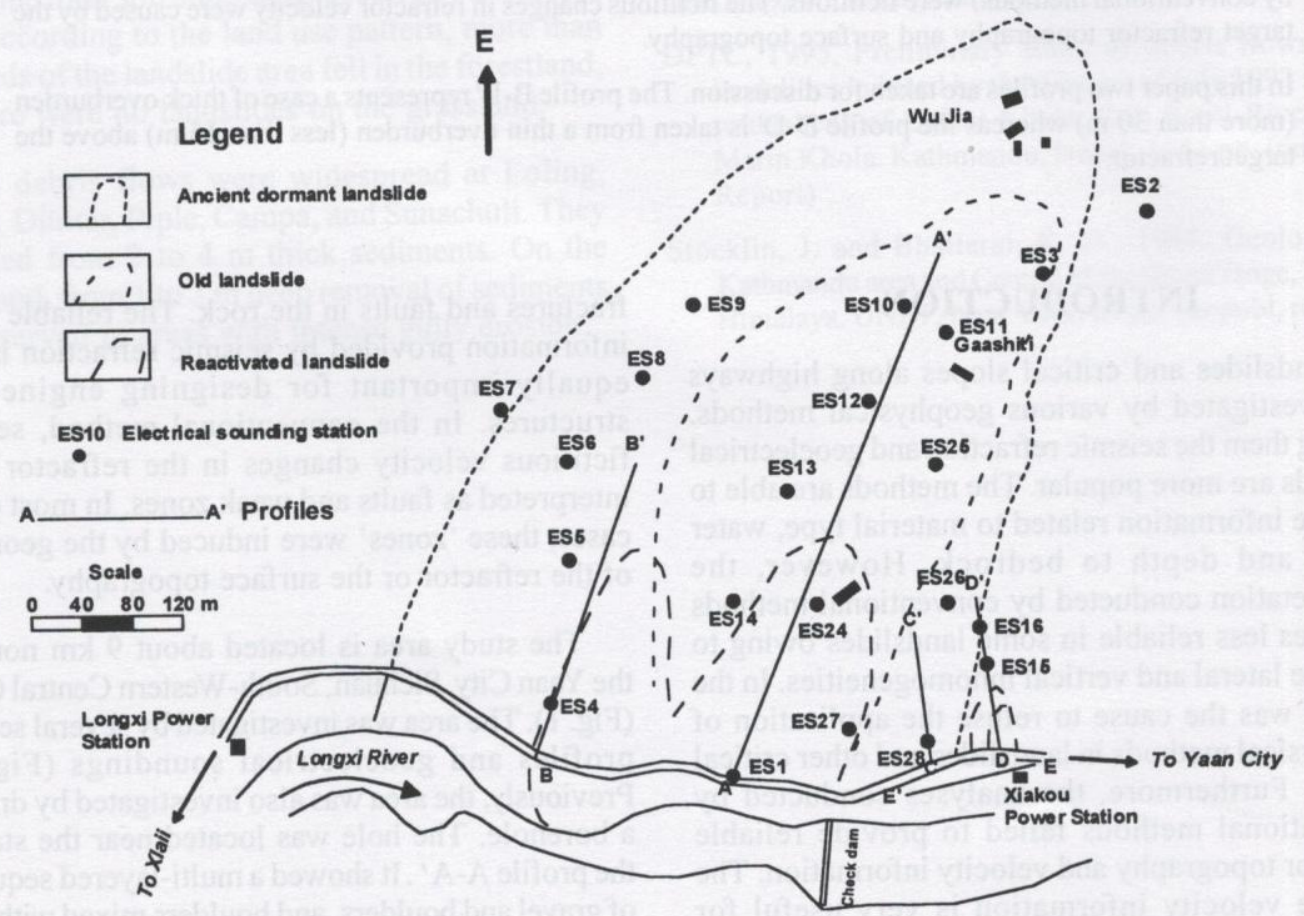

Fig. 2: Locations of seismic profiles and electrical soundings in the Xiakou Landslide, China 
The main aim of this paper is to present the usefulness of the Generalised Reciprocal Method (GRM) of data processing. It minimises the errors in depth and velocity calculations caused by undetected layers, velocity inversions, geometry of target refractor, and surface topography. The elementary approach to refraction surveying and interpretation is unacceptable; as it incorporates no procedures for identifying lateral velocity changes, dip of the refractor, or the presence of undetected layers (Lankston 1990). The concept of high resolution, therefore, should not convey merely an image of density of surface data points and timing precision, but rather of the improvement of the subsurface information (Lankston 1990). The GRM is considered to be better than other conventional reciprocal methods. Spreadsheet interpretations of seismic refraction data are more popular for the PlusMinus Method (Fourie and Odgers 1995). Although there are many types of commercially available software, the GRM can also be executed by using a spreadsheet such as Microsoft Excel. The graphical presentations of the Excel spreadsheet are quite useful for the selection of optimum parameters of the GRM.

\section{ACQUISITION AND PROCESSING METHODS}

Seismic refraction studies were conducted in five profiles of varying lengths. The profiles $A-A^{\prime}$ and B-B' were of multiple spreads and others were of a single spread. Each spread had one long and one short offset shots at each end of the spread. In the profiles $A-A^{\prime}$ and $B-B^{\prime}$, each spread overlapped the next by two geophone positions. For the seismic source, about $200 \mathrm{~g}$ and $100 \mathrm{~g}$ of explosives were used respectively for the long and short offset shots. Special care was taken to achieve good coupling between ground motion and geophones.

The data were recorded by using the12-channel seismograph BISON GeoPro 8012A. The distances between adjacent geophones were $10 \mathrm{~m}$ for the profiles $A-A^{\prime}$ and $B-B^{\prime}$, and 5-7 m for the other ones.

Immediately after the completion of the fieldwork, the data were interpreted by using the conventional Plus-Minus Method. In an area of thick overburden, the depths calculated by the Plus-Minus Method and electrical soundings were different. There were significant (more than two times) discrepancies between the depths calculated by the two methods.

\section{Phantoming}

In routine field operations, obtaining a reciprocal time through direct measurement is difficult. The forward and reverse reciprocal times must agree within a few per cent. To meet this criterion during the processing, data were phantomed by using endto-end phantoming procedures described by Lankston and Lankston (1986). The phantoming procedures help to find reliable reciprocal time and to save field time and expenses. Phantoming can be applied successfully even when the first arrivals in a far-shot seismogram are difficult to recognise. Subsequently, a lower amount of dynamite is sufficient. With the help of phantoming procedures, a profile with multiple shots can be combined to make one profile for further processing without loosing any details. Before processing the data by the GRM, travel time was interpolated between each observed or phantomed point. Interpolation was conducted mainly for those profiles where geophone spacing was $10 \mathrm{~m}$. It was done in an attempt to improve the resolution of the optimum $X Y$ value. It made the recording equivalent to $5 \mathrm{~m}$ of geophone spacing.

\section{Velocity Analysis}

The velocity analysis forms an initial part of the GRM. The velocity analysis function $t_{v}$ is defined by the equation (Palmer 1981):

$$
t_{v}=\left(t_{A Y}-t_{B X}+t_{A B}\right) / 2
$$

where, $t_{A Y}$ and $t_{B X}$ are the arrival times for head waves (from forward and reverse shots) that have emerged from the same point in the refractor and arrived at locations $Y$ and $X$ at the surface, and $t_{A B}$ is the reciprocal time.

The value of this function is referred to as $G$, which is the midway between $X$ and $Y$. For the PlusMinus method $X Y=0 \mathrm{~m}$, which means the waves that emerge from the same point in the refractor arrive at the same point $G$ on the surface. In the GRM, the velocity analysis is conducted by using Palmer's minimum detail criterion (Palmer 1981): the selected curve should exhibit the least amount of irregularity. Selection of a particular curve defines the optimum 
$X Y$ value that is to be used in the later stages of data processing. The derivative of the velocity analysis function with respect to position along the line is the reciprocal of the velocity at that position. The derivative can be taken at any point so that the velocity of the refractor can be determined continuously. The velocity analysis function (equation 1) is not affected by the dip of the refractor, the dip or velocity of any overlying layer, or the surface topography (Palmer 1981). In contrast, any changes in slope of the velocity analysis graph indicate the lateral position of velocity changes in the target refractor.

\section{Time-to-depth Migration}

The process of migration is important for both the seismic refraction and reflection data interpretations. The interpretations for time-to-depth migration are accomplished in two stages. The first stage is the calculation and interpretation of the timedepth function (Palmer 1981)

$$
t_{G}=\left(t_{A Y}+t_{B X}-\left(t_{A B}+X Y / V_{n}\right) / 2\right.
$$

where, $V_{n}$ is the refractor velocity determined from velocity function.

The time-depth function overcomes the errors related to dip, includes separation of geophone and shot point delay times, migration, and convergence correction into a single operation (Palmer 1981).

At the second stage, the time-depth analysis is conducted by using Palmer's maximum detail criterion. The time-depth analysis shows more details of the target refractor topography than the topography obtained by conventional methods ( $X Y$ $=0 \mathrm{~m}$ ). The optimum values for $X Y$ that satisfy the Palmer's criteria for velocity and time-depth analysis are chosen. The optimum $X Y$ values for both the velocity analysis and time-depth functions should be the same. In case of discrepancies, re-analysis can be done. Palmer (1981) described other methods of estimation of optimum XY values that can serve as guidance during the processing of data by applying the GRM.

One of the main advantages of the GRM of is the calculation of average velocity above the target refractor without defining all the layers. The average velocity is analogous to the determination of stacking velocity from normal moveout measurements in reflection processing (Palmer, 1981). The expression for the calculation of the average velocity is

$$
\bar{V}=\sqrt{\frac{V_{n}^{\prime 2} X Y}{X Y+2 t_{G} V_{n}^{\prime}}}
$$

The major advantage of this average velocity is that the depth to the refractor is not needed. The total thickness of all the layers above the refractors can be computed by the following equation

$$
\sum_{j=1}^{n-1} Z_{j G}=\frac{t_{G} \bar{V}}{\operatorname{Cos} \bar{i}} \quad \text { where, } \bar{i}=\operatorname{Sin}^{-1}\left(\frac{\bar{V}}{V_{n}^{\prime}}\right)
$$

\section{ANALYSIS OF PROCESSED RESULTS}

All profiles were processed by applying the GRM. The analysis and calculations carried out for the two profiles are presented here. The profile B$\mathrm{B}^{\prime}$ represents an area of thick overburden (more than $30 \mathrm{~m}$ ) whereas the profile $\mathrm{D}^{-\mathrm{D}^{\prime}}$ lies in an area with thin overburden (less than $15 \mathrm{~m}$ ) above the target refractor.

\section{Profile B-B'}

The depth obtained from the electrical sounding at the lower part of the profile was about $40 \mathrm{~m}$ and the depth given by the Plus-Minus Method (case $X Y=0 \mathrm{~m}$ ) was about $30 \mathrm{~m}$. The discrepancies between the depths calculated by the two methods were higher in the profile $\mathrm{A}-\mathrm{A}^{\prime}$. The average electrical resistivity of intermediate layer in the profile $A-A^{\prime}$ was less than that in the profile $\mathrm{B}^{-\mathrm{B}^{\prime}}$. It indicated the presence of more clayey materials in the intermediate layers of the profile $A-A^{\prime}$. On the other hand, clayey materials are more sensitive to differential compaction. It creates a linear increase of velocity with the depth, and with the increase of depth to the refractor, the possibilities of having undetected layers increase.

The velocity analysis curves for the profile B$B^{\prime}$ are presented in Fig. 3. The curves were calculated for varying XY values from 0 to $60 \mathrm{~m}$ at a step of $5 \mathrm{~m}$. The velocity curve for $X Y=0 \mathrm{~m}$ indicates several changes that can be inferred as velocity changes along the refractor profile. These velocity 
High resolution seismic refraction data interpretation: an example from Xiakou landslide, China

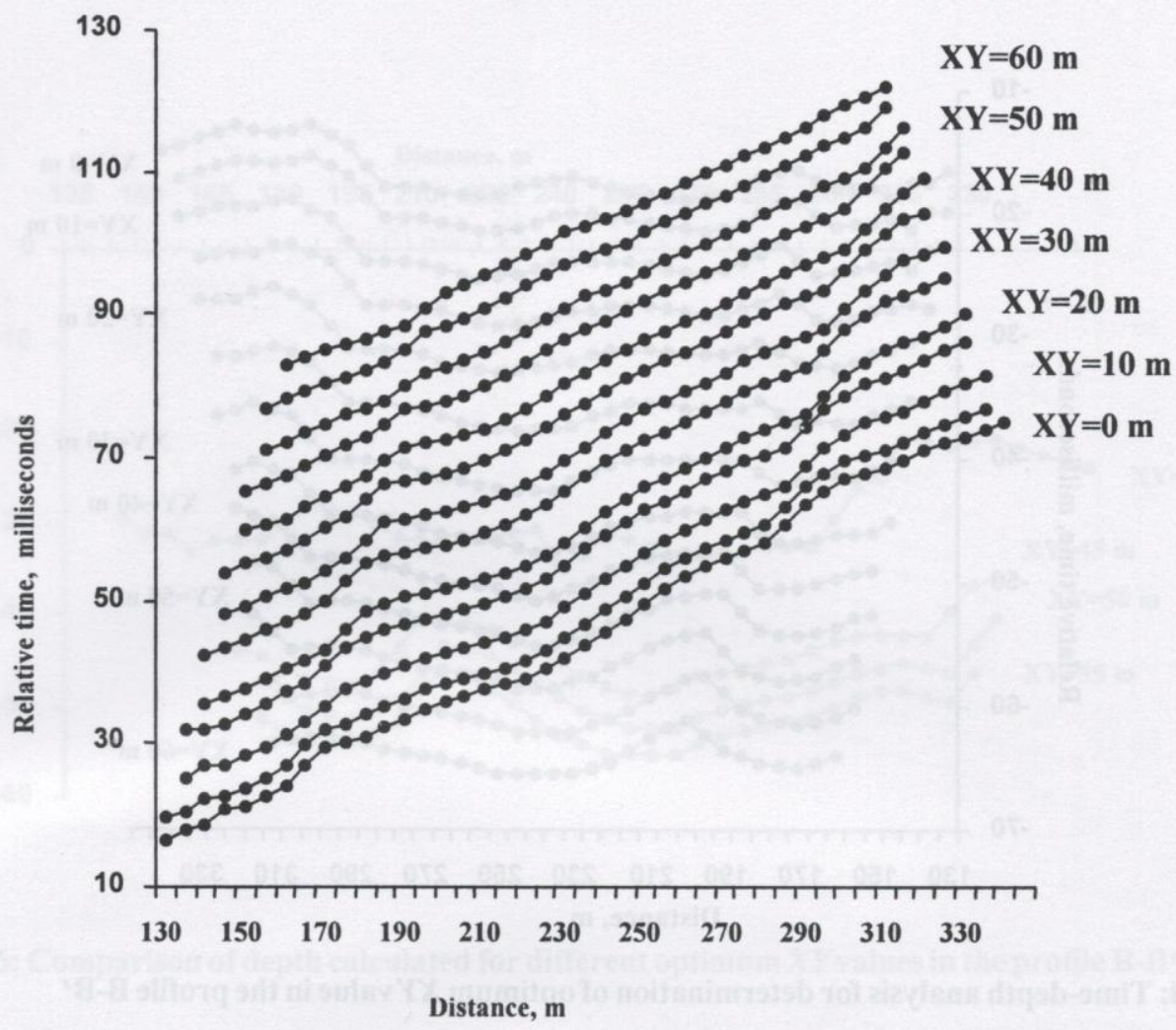

Fig. 3. Velocity analysis for determination of optimum $X Y$ value in the Profile B-B'

changes can be fictitious. The velocity changes calculated for $X Y=0 \mathrm{~m}$ were $3077 \mathrm{~m} / \mathrm{s}, 4762 \mathrm{~m} / \mathrm{s}$, $2800 \mathrm{~m} / \mathrm{s}$, and $5000 \mathrm{~m} / \mathrm{s}$. The fictitious velocity changes usually occur because of irregular refractor topography. The higher velocity zones between the two lower velocity zones in the bedrock were related to the topographical effects. These high velocity values are not compatible with the rock type in the study area. By applying Palmer's least detail criterion for the velocity analysis curve, the optimum $X Y=$ $45 \mathrm{~m}$ was selected for further processing. The selection process can be somehow subjective, and one may choose nearby values such as $X Y=50 \mathrm{~m}$ or $55 \mathrm{~m}$.

The time-depth analysis curves were calculated by using the time-depth function (equation 2 ). The time-depth curves for optimum $X Y$ give the shape of the refractor in time (see Fig. 4). The curves were calculated for $X Y$ values ranging from 0 to $60 \mathrm{~m}$ at a step of $5 \mathrm{~m}$. According to Palmer (1981), the curve that gives the maximum details should be selected.
The optimum $X Y$ value selected for both the velocity and time-depth analysis curves should be the same. The time-depth analysis curves indicated that the curves for $X Y=45,50$, and $55 \mathrm{~m}$ gave the maximum details.

The depths along the profile B-B' were calculated by using the average velocity (equation 3 ). The average velocities along the profile B-B' for the possible optimum XY values are presented in Fig. 5. The depths calculated for the possible optimum $X Y$ values and for $X Y=0 \mathrm{~m}$ are presented in Fig. 6, and the final migrated sections calculated for the optimum $X Y=45 \mathrm{~m}$ are presented in Fig. 7 . Figure 6 shows that the depths calculated for $X Y=$ $0 m$ are lower than those of the optimum XY values.

\section{Profile D-D'}

The electrical soundings indicated that the depth to rock was about $14 \mathrm{~m}$ in the central part of the profile. The velocity analysis curve presented in Fig. 
Surendra Raj Pant et al.

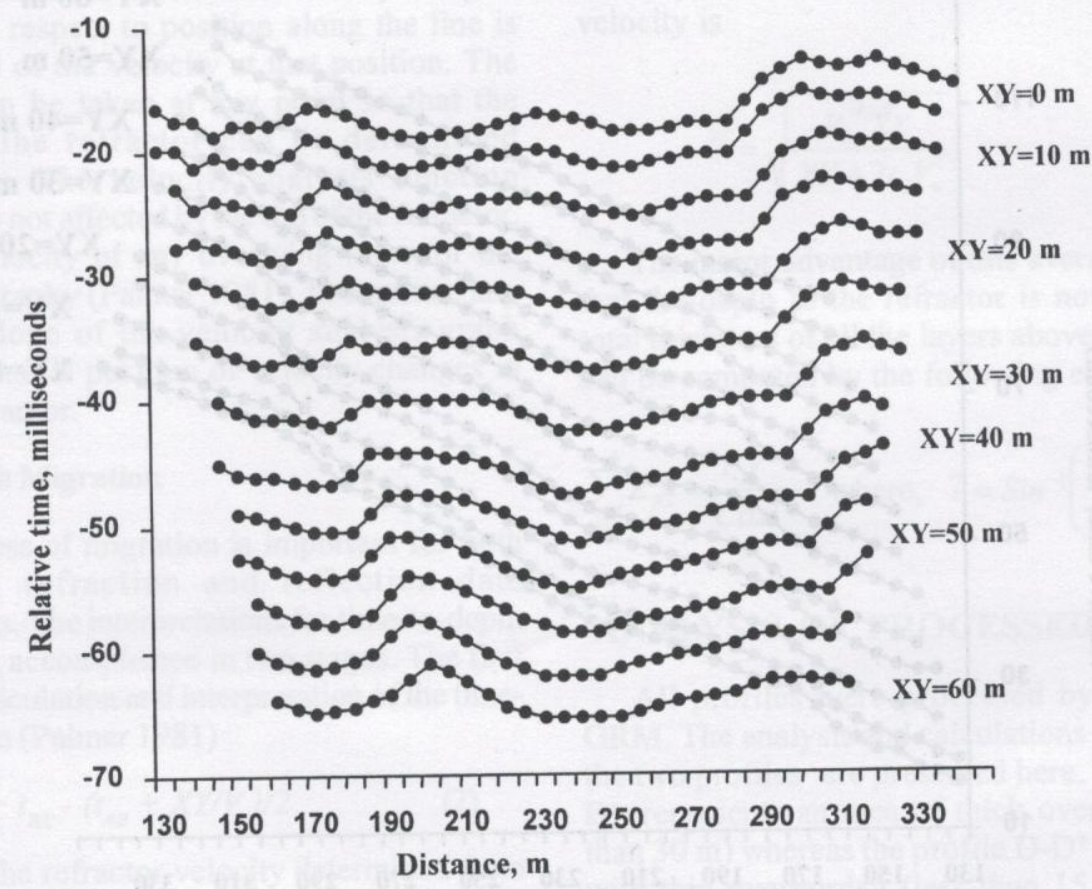

Fig. 4: Time-depth analysis for determination of optimum $X Y$ value in the profile B-B'

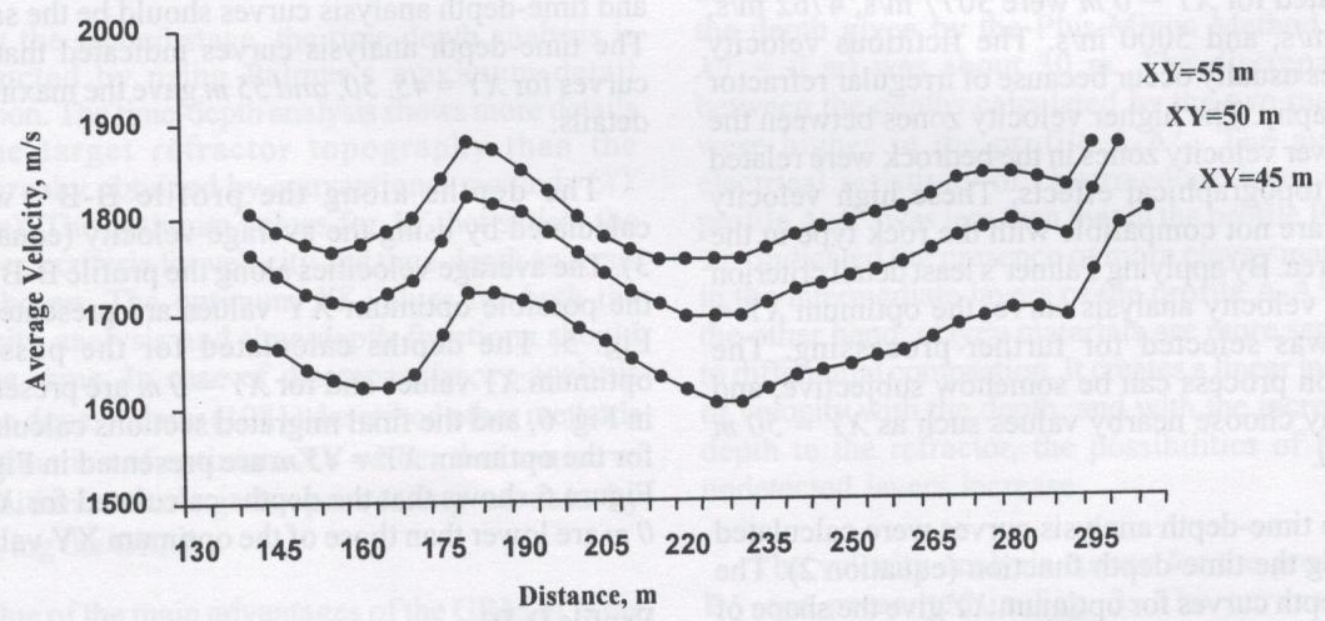

Fig. 5: Average velocities calculated for different possible optimum $X Y$ values in the profile B-B' 
High resolution seismic refraction data interpretation: an example from Xiakou landslide, China

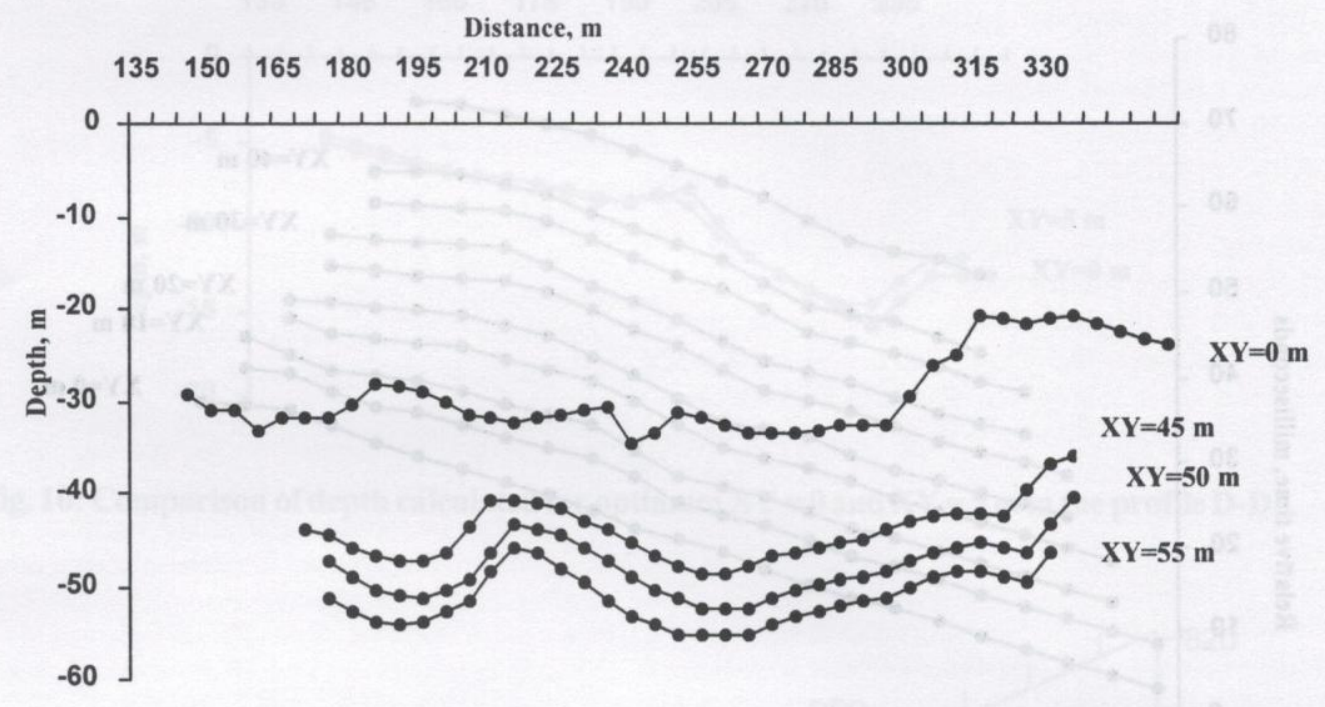

Fig. 6: Comparison of depth calculated for different optimum $X Y$ values in the profile B-B'

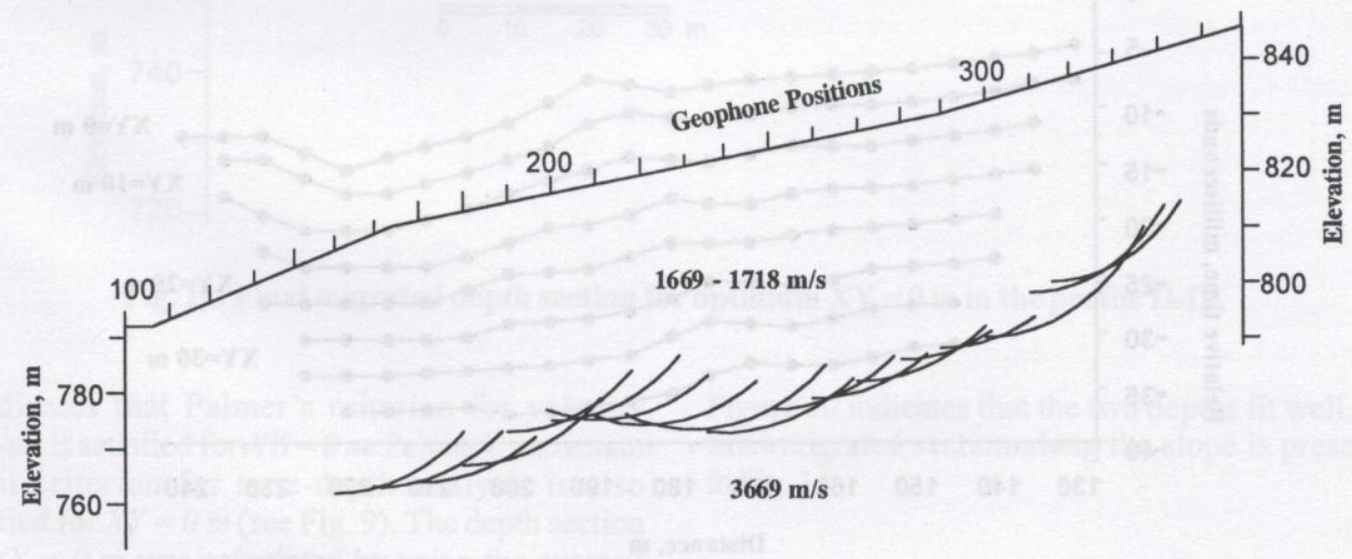

Fig. 7: Final migrated depth section for optimum $X Y=45 m$ in the profile B-B' 
Surendra Raj Pant et al.

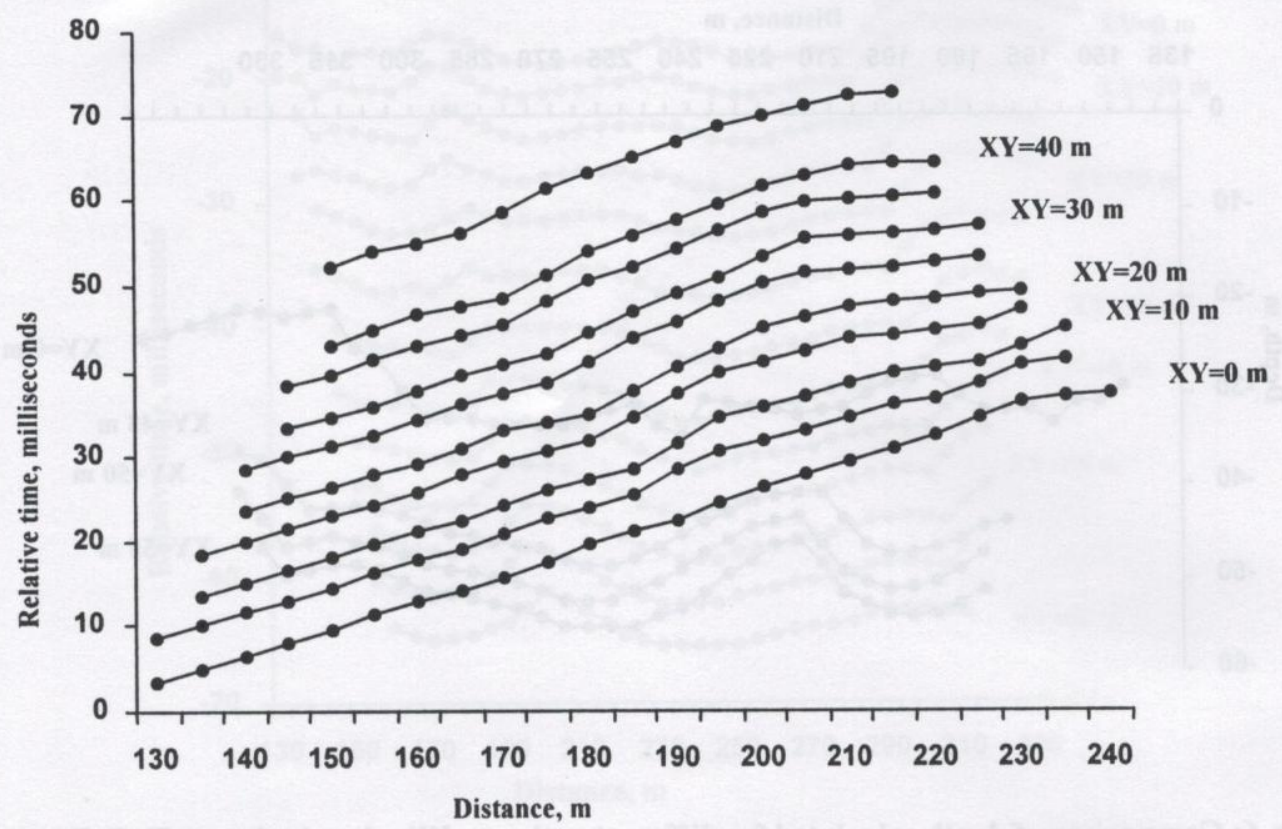

Fig. 8: Velocity analysis for determination of optimum XY value in the Profile D-D'

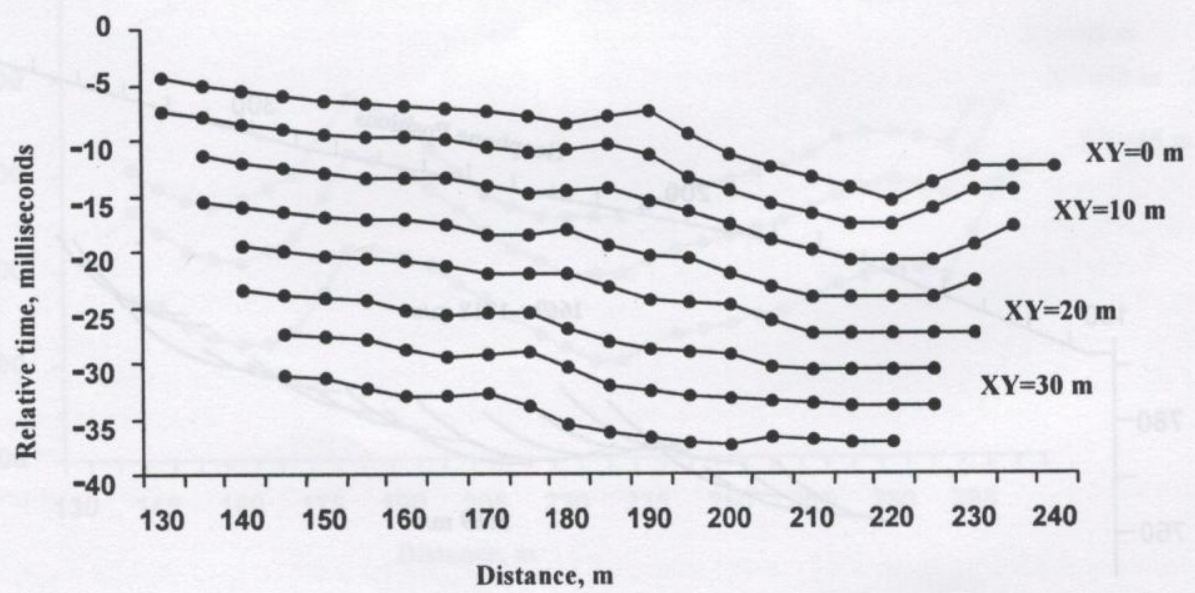

Fig. 9: Time-depth analysis for determination of optimum XY value in the profile D-D' 
High resolution seismic refraction data interpretation: an example from Xiakou landslide, China

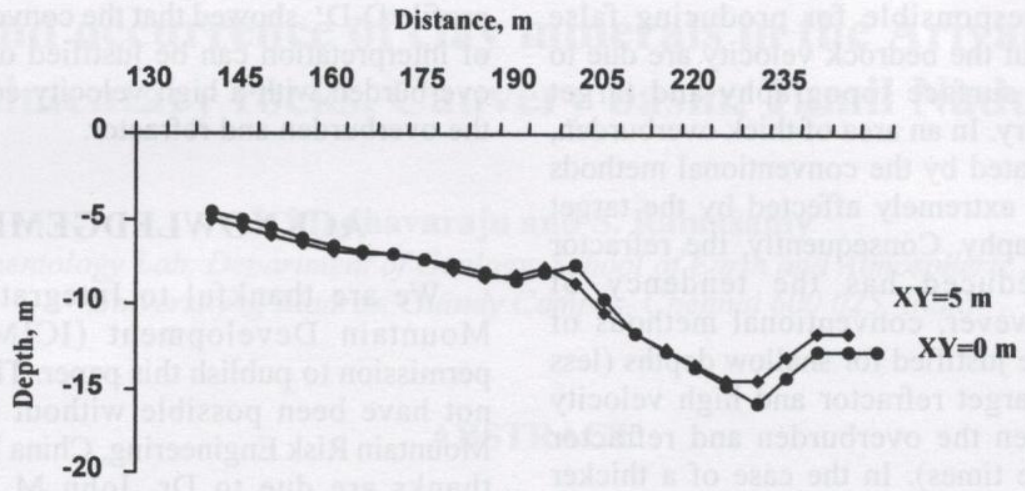

Fig. 10: Comparison of depth calculated for optimum $X Y=0$ and $X Y=5 \mathrm{~m}$ in the profile D-D'

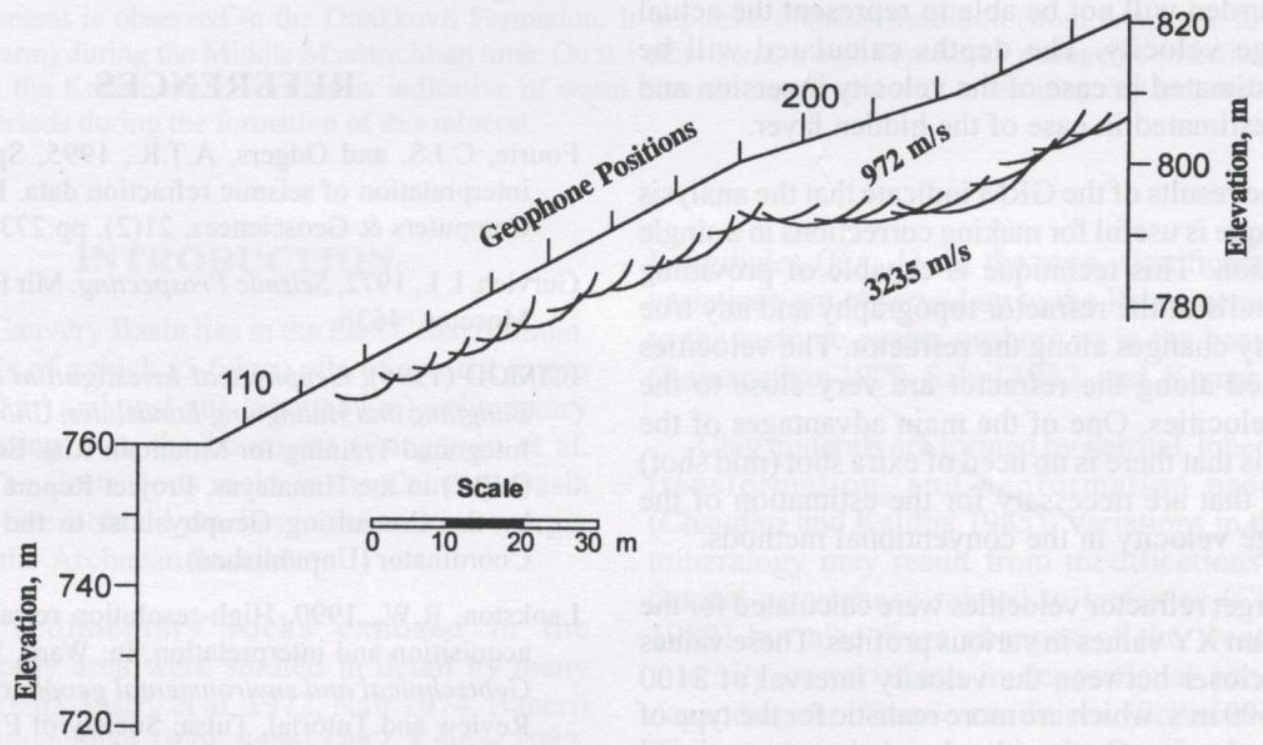

Fig. 11: Final migrated depth section for optimum $X Y=0 \mathrm{~m}$ in the profile D-D'

8 indicates that Palmer's criterion for velocity analysis is satisfied for $X Y=0 \mathrm{~m}$. Palmer's maximum detail criterion for time-depth analysis is also satisfied for $X Y=0 m$ (see Fig. 9). The depth section for $X Y=0 \mathrm{~m}$ was calculated by using the average velocity estimated from the effective velocity. It was compared with the depth calculated for $X Y=5 \mathrm{~m}$. In the latter case, the average velocity of the overburden was estimated by using Palmer's formula.
Figure 10 indicates that the two depths fit well. The final migrated section along the slope is presented in Fig. 11.

\section{CONCLUSIONS}

The principal problem in investigating landslides and other critical slopes is related to extreme lateral changes in seismic wave propagation characteristics 
due to the changes in material type of overburden. Other factors responsible for producing false information about the bedrock velocity are due to the changes in surface topography and target refractor geometry. In an area of thick overburden, velocities calculated by the conventional methods $(X Y=0 \mathrm{~m})$ are extremely affected by the target refractor topography. Consequently, the refractor topography deduced has the tendency of smoothing. However, conventional methods of interpretation are justified for shallow depths (less than $15 \mathrm{~m}$ ) to target refractor and high velocity contrasts between the overburden and refractor (more than three times). In the case of a thicker overburden (in a landslide or critical slope), it is more likely that the overburden may consist of layers of different materials corresponding to different velocity layers. In such a situation, the conventional method of estimation of average velocity for the overburden will not be able to represent the actual average velocity. The depths calculated will be overestimated in case of the velocity inversion and underestimated in case of the hidden layer.

The results of the GRM indicate that the analysis technique is useful for making corrections in a single operation. This technique is capable of providing the details of the refractor topography and any true velocity changes along the refractor. The velocities obtained along the refractor are very close to the true velocities. One of the main advantages of the GRM is that there is no need of extra shot (mid shot) points that are necessary for the estimation of the average velocity in the conventional methods.

Target refractor velocities were calculated for the optimum XY values in various profiles. These values came closer between the velocity interval of 3100 and $3600 \mathrm{~m} / \mathrm{s}$, which are more realistic for the type of rock in the site. On the other hand, the conventional method indicated velocity variations in a wide range: from 2500 to $5000 \mathrm{~m} / \mathrm{s}$. It showed several velocity changes within the above-mentioned range, which is not compatible with the bedrock geology. The depths calculated by the conventional method were shallower than those of the GRM for the profile

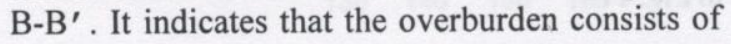

hidden layers. The analysis of the data along the profile D-D' showed that the conventional method of interpretation can be justified only for shallow overburden with a high velocity contrast between the overburden and refractor.

\section{ACKNOWLEDGEMENTS}

We are thankful to Integrated Centre for Mountain Development (ICIMOD) for the permission to publish this paper. This study would not have been possible without the support of Mountain Risk Engineering, China Project. Special thanks are due to Dr. John M. Reynolds for suggestions and comments on the processed data. We are indebted to our colleagues in the Institute of Mountain Disasters and Environment, Chinese Academy of Sciences, for the help extended to us during the fieldwork.

\section{REFERENCES}

Fourie, C.J.S. and Odgers, A.T.R., 1995, Spreadsheet interpretation of seismic refraction data. Pergamon, Computers \& Geosciences, 21(2), pp.273-277.

Gurvich, I. I., 1972, Seismic Prospecting. Mir Publishers, Moscow, 463p.

ICIMOD (1996), Geophysical Investigation of Xiakou, Bangfang and Huanglung Landslides, China Project, Integrated Training for Mountain Risk Engineering (MRE) in the Himalayas. Project Report submitted by the Consulting Geophysicist to the Regional Coordinator (Unpublished).

Lankston, R.W., 1990, High-resolution refraction data acquisition and interpretation. In: Ward, S.H. (ed.), Geotechnical and environmental geophysics, Vol. I: Review and Tutorial, Tulsa: Society of Exploration Geophysicists, pp.45-73.

Lankston, R. W., and Lankston, M. M., 1986, Obtaining multilayer reciprocal times through phantoming, Geophysics, 51, pp.45-49.

Palmer, D., 1981, An introduction to generalized reciprocal method of seismic refraction interpretation: Geophysics, 46, pp.1508-1518. 